Back-analysis and finite element modeling of jacking forces in weathered rocks

D E L Ong and C S Choo

\title{
HIGHLIGHTS
}

- A novel approach is proposed for pipe-jacking through weathered geology.

- Nonlinear rock strength parameters were developed to assess pipe-jacking forces.

- Higher rock strength leads to arching, which reduces pipe-rock friction and jacking forces.

- 3D FEM confirms reliability of direct shear test results in assessing jacking forces. 


\section{Back-analysis and finite element modeling of jacking forces in weathered rocks}

D E L Ong ${ }^{1, *} ; \mathrm{C} \mathrm{S} \mathrm{Choo}^{2}$

3 Abstract: Prediction of jacking forces has been well-established for pipe-jacking drives traversing soils. However, the accrual of jacking forces for drives negotiating weathered rock

5 formations has not been well understood. Three pipe-jacking drives in Kuching City, 6 Malaysia spanning weathered lithological units of sandstone, phyllite and shale were studied.

7 In the absence of in-situ pressuremeter testing during the investigation stage, tunneling rock

8 spoils were collected and characterized through direct shear testing. The "generalized 9 tangential" technique was applied to the nonlinear direct shear test results to obtain linear Mohr-Coulomb parameters, $c_{p}^{\prime}$ and $\phi_{p}^{\prime}$. This allowed for back-analysis of frictional 11 coefficient, $\mu_{\text {avg }}$ through the use of a well-established predictive jacking force model. The 12 reliability of using $c^{\prime}{ }_{p}, \phi_{p}{ }_{p}$ and $\mu_{\text {avg }}$ was assessed through $3 \mathrm{D}$ finite element modeling of the studied pipe-jacking drives. Based on these parameters, the results obtained from the numerical analyses of the studied pipe-jacking drives show good agreement with the jacking forces measured in-situ. The outcome of this research demonstrates that the derived strength parameters from direct shear testing of tunneling rock spoils has the potential to be used as reliable input parameters in finite element modeling to predict pipe-jacking forces in highly weathered geological formations.

Keywords: Pipe-jacking; Friction; Direct shear; Rocks; Finite element modeling

${ }^{1}$ Director (Acting), Research Centre for Sustainable Technologies, Faculty of Engineering, Science \& Computing, Swinburne University of Technology, Sarawak Campus, 93350 Kuching, Sarawak, Malaysia.

${ }^{2}$ Associate Lecturer, Research Centre for Sustainable Technologies, Faculty of Engineering, Science \& Computing, Swinburne University of Technology, Sarawak Campus, 93350 Kuching, Sarawak, Malaysia.

*Corresponding author. Tel.: +6082 260631; E-mail: elong@swinburne.edu.my 


\section{INTRODUCTION}

The understanding of pipe-jacking forces is critical in project planning and cost estimation of underground infrastructure projects. Such was the case in the installation of $7.7 \mathrm{~km}$ trunk sewerage pipelines within the central business district of Kuching City, Malaysia. The microtunneling works traversed the young pre-upper carboniferous Tuang formation, characterized by tightly folded, highly fractured lithological units of shale, phyllite, and sandstone (Tan, 1993).

As a result of the highly fractured geology, the extracted rock cores were scarcely intact. The majority of recovered cores from the studied pipe-jacking drives had Rock Quality Designation (RQD) values of zero. Intact rock core lengths are necessary for common rock strength tests, such as uniaxial compression strength (UCS), and point load. The lack of intact rock cores created challenges in assessing the in-situ strength parameters of the highly fractured weathered rock lithological units. The situation was made worse as in-situ pressuremeter tests were not locally available and were not budgeted during the investigation stage of the project. As rock strength parameters were essential in the prediction of jacking forces, the lack of any reliable rock strength values impeded further efforts in assessing jacking loads accrued during pipe-jacking works.

The work described in this paper was motivated by the need to characterize rock mass strength of the various highly fractured lithological units found within the Tuang Formation in Kuching City. Hence, a novel approach by reconstituting tunneling rock spoils obtained during the construction stage of the project was proposed to characterize the rock strengths for subsequent use in the back-analysis and prediction of jacking forces. The use of tunneling rock spoils for the purpose of back-analyzing jacking forces was explored (Choo and Ong, 2012, 2014, 2015), where rock spoils from tunneling works were reconstituted and scalped for direct shear testing. Based on field measured jacking forces, the direct shear test results of 
$c^{\prime}$ and $\phi^{\prime}$ were applied to a well-established empirical jacking force predictive model (PelletBeaucour and Kastner, 2002) to reliably back-analyze soil-pipe frictional coefficients. In this paper, finite element analysis was used as a tool to assess the reliability of applying

60 the strength parameters obtained from direct shear testing to predict jacking forces and 61 compare against corresponding field measured values.

\subsection{Direct shear testing}

Iscimen (2004) developed an apparatus capable of measuring soil-pipe interface shear stresses for curved surfaces, such as that on the outer peripheral of jacked pipes. The apparatus was outfitted with interchangeable inner walls to allow for testing at different pipe curvatures. Various sands were tested against pipes made from different materials. The soilpipe interface strength was found to increase with surface roughness, up to an upper limit "critical roughness", beyond which the influence of surface roughness on shear strength value was negligible. This value corresponded with the internal shear strength of the soil. This observation was similar to that made by Kishida and Uesugi (1987). The study found that particle shape greatly affected the soil-pipe interface shear strength, with angular particles exhibiting stronger interlocking than sub-rounded particles, and this is an important observation for the work presented in this paper as both argillaceous and arenaceous materials are tested.

Staheli (2006) conducted interface direct shear testing on various commonly available pipe materials, using sands. Interface friction values were developed from the tests and applied to field case studies for comparison. From analyses of the measured jacking forces for unlubricated sections of the case studies, a frictional pipe-jacking force model was developed to estimate normal stresses acting along the pipeline. The pipe-jacking force model was based on Terzaghi's arching theory. However, usage of the model is restricted to unlubricated pipe- 
81 jacking drives. The work showed that the direct shear test is capable of obtaining useful strength parameters for the assessment of jacking forces in unlubricated pipe-jacking drives. properties of various lubricants. A discrete lubricating layer was introduced between a concrete block and a soil mass. This would simulate the soil-pipe interaction in pipe-jacking at the pipe invert. It was found that the combination of plasticizer with polymer was most effective in reducing jacking forces due to frictional resistance. The findings from the large scale frictional test were applied to two sections (one linear and one curved) of a pipe-jacking case study in Taiwan. The analyses of jacking forces using frictional coefficients from the experiment resulted in overestimation of the jacking forces when compared against site measurements. This discrepancy was attributed to overestimation of the soil-pipe contact area. Shou et al. (2010) showed that the direct shear test can be used to assess jacking forces for lubricated drives.

Choo and Ong (2015) evaluated pipe-jacking forces accrued through drives in highly fractured and weathered rock. Equivalent strength parameters based on nonlinear power law functions were obtained from direct shear testing of reconstituted tunneling rock spoils. These strength parameters were subsequently applied to a well-established jacking force model by Pellet-Beaucour and Kastner (2002). Interpreted values of frictional coefficient, $\mu_{\text {avg }}$ for various weathered lithological units were analyzed against jacking forces, lubrication

100 patterns and stoppages for consistency. The authors found that the use of reconstituted 101 tunneling rock spoils was reliable in the analyses of jacking loads for drives traversing weathered rock formations. Hence, the use of finite element modeling in the current paper is a natural extension of the established work by Choo and Ong (2015).

The various studies presented above that involve interface friction and soil-structure interaction have clearly indicated that direct shear testing can be used to study jacking forces. 
106 The applicability of direct shear testing allows for the characterization of rock strength during

107 the construction stage, and subsequent back-analyses of measured jacking forces. This is

108 significant in light of the unavailability of in-situ testing methods (such as the pressuremeter

109 test) during the early investigative stage of the project. The suitability of using direct shear

110 test results from reconstituted tunneling rock spoils for the back-analyses of jacking forces

111 can be validated through 3D finite element analysis.

\section{1.2. Jacking force models}

113 Jacking force models are typically dependent on the geology traversed during pipe-jacking

114 (Chapman and Ichioka, 1999; Osumi, 2000; Staheli, 2006). The majority of these models are well-developed for predicting pipe-jacking forces when traversing soils. Such models usually rely on the shear strengths of the traversed geomaterials, which are typically characterized by the Mohr-Coulomb model. Frictional coefficients for different combinations of soil-pipe materials are often developed empirically. There are very limited provisions made for strength characterization and values of frictional coefficients for pipe-jacking involving rockstructure interaction. This study proposes a novel method for obtaining equivalent rock strength properties for use in the analysis of jacking forces using a well-established jacking force equation developed by Pellet-Beaucour and Kastner (2002).

Pellet-Beaucour and Kastner (2002) developed a predictive jacking force equation based on nine microtunneling operations in France. The model postulated that normal stresses acting on the outer periphery of the pipe resulted from ground overburden pressure. As a pipeline is buried at depth, the phenomenon of soil arching becomes relevant in understanding the contact stresses acting on the pipe. The phenomenon of soil arching was observed by Terzaghi (1936) by the downward deflection of a trap door underlying a sand mass. The opening of the trap door is analogous to the excavation of a tunnel. This disturbance to the geostatic conditions induces a redistribution of soil stresses, principally 
131 oriented to the tunnel perimeter. The soil stresses acting normal to the trap door (or tunnel in

132 this case) are relaxed, thus reducing the contact stresses on the outer surface of any installed

133 structure, i.e. jacked pipes in a microtunneling operation. The model developed by Pellet-

134 Beaucour and Kastner (2002) was preferred for use in this paper due to its consideration of

135 arching effect. This predictive jacking force model is shown in Eq. (1),

$136 \quad F=\mu L D_{e} \frac{\pi}{2}\left[\left(\sigma_{E V}+\frac{\gamma D_{e}}{2}\right)+K_{2}\left(\sigma_{E V}+\frac{\gamma D_{e}}{2}\right)\right]$

137 in which $F$ is the total frictional jacking force; $L$ is the pipe span; $D_{e}$ is the outer pipe 138 diameter; $\sigma_{E V}$ is the vertical soil stress at the pipe crown; $\gamma$ is the soil unit weight; and $K_{2}$ is

139 the thrust coefficient of soil acting on the pipe, with a suggested value of 0.3 (French Society

140 for Trenchless Technology, 2006). $\mu$ is the coefficient of soil-pipe friction, given in Eq. (2) as

$141 \mu=\tan \delta$

142 where $\delta$ is the soil-pipe friction angle. Previous studies have empirically assumed $\delta$ to be half 143 the internal soil friction angle, $\phi$ (Sofianos et al., 2004; Staheli, 2006). More realistically,

144 Stein et al. (1989) recommended values of $\mu$ for various states of friction encountered during

145 pipe-jacking. In lubricated drives, $\mu$ was recommended to be between $0.1-0.3$. Various

146 studies have used these values of $\mu$ as a basis for identifying lubricated drives through soil

147 and rock (Barla et al., 2006; French Society for Trenchless Technology, 2006; Pellet-

148 Beaucour and Kastner, 2002).

149 The vertical soil stress at the pipe crown, $\sigma_{E V}$ is determined by the soil cohesion, $C$; the

150 soil internal friction angle, $\phi$; the lateral earth pressure coefficient, $K$; $h$ is the soil cover from

151 the ground level to the pipe crown; and the influencing soil width above the pipe, $b$;

$152 \sigma_{E V}=\frac{b\left(\gamma-\frac{2 C}{b}\right)}{2 K \tan \phi}\left(1-e^{-2 K \frac{h}{b} \tan \phi}\right)$ 
$153 \quad b=D_{e}\left(1+2 \tan \left(\frac{\pi}{4}-\frac{\phi}{2}\right)\right)$

$154 \sigma_{E V}$ is derived from Terzaghi's limit equilibrium approach for estimating the vertical stresses

155 acting on the roof of a tunnel (Terzaghi, 1943). The excavation of a tunnel was synonymous

156 with the deflection of a trapdoor beneath a sand mass. The creation of a tunnel results in

157 localized stress redistribution around the tunnel, which could result in a decrease in vertical

158 stresses at the tunnel roof. This reduces the normal stresses acting on the pipe crown,

159 resulting in reduced frictional jacking forces. The understanding of $\sigma_{E V}$ is therefore significant

160 in anticipating the magnitude of jacking forces. The formulation of $\sigma_{E V}$ shows a dependence

161 on Mohr-Coulomb (MC) strength parameters, $c^{\prime}$ and $\phi^{\prime}$. These MC parameters are difficult to

162 evaluate as the rock cores extracted from the Tuang Formation were highly fractured.

163 1.3. Arching ratio

164 From Terzaghi's trapdoor experiment, several studies have been conducted to quantify the effects of arching. McNulty (1965) assessed the degree of soil arching induced by a yielding trapdoor by examining values of arching ratio. McNulty (1965) defined arching ratio as the

167 ratio of the load on the yielded door to the load on the undeflected door. This arching ratio

168 was expressed as

$169 \rho=\frac{P_{B}}{P_{S}}$

170 where $\rho=$ arching ratio; $P_{B}=$ average pressure acting on the trapdoor; and $P_{S}=$ surcharge

171 pressure acting on the surface of a soil mass. An arching ratio less than 1.0 implied the

172 presence of active arching, while an arching ratio greater that 1.0 was indicative of passive

173 arching. Based on McNulty's study, similar expressions of arching ratio were formulated for

174 reinforced embankments to estimate effect of arching in the embankment fill (Borges and 
175 Marques, 2011; Deb, 2010; Han and Gabr, 2002; Ye et al., 2012). Abbott (1967) theorized a

176 similar formulation for arching ratio applied to buried structures, given as

$177 \quad A_{\sigma}=\frac{p_{t}}{p_{o}}=\frac{p_{o}+p_{a}}{p_{o}}$

178 where $A_{\sigma}$ is the arching ratio; $p_{t}$ is the total average axial stress carried by structure; $p_{o}$ is the

179 static overpressure; and $p_{a}$ is the average axial stress sustained by structure due to arching. $p_{o}$

180 refers to additional static loading. Lee et al. (2006) offered a similar expression of arching

181 ratio in terms of the change in vertical stresses due to tunneling, given as

$182 \quad A R(\%)=\frac{\Delta \sigma_{v}}{\sigma_{v o}} \times 100$

where $A R$ is the arching ratio; $\Delta \sigma_{v}$ is the change in vertical stress during tunneling; and $\sigma_{v o}$ is the total overburden pressure. These equations will be subsequently used to verify the presence of arching in the various pipe-jacking drives presented in this study.

\section{STRENGTH CHARACTERIZATION OF RECONSTITUTED TUNNELING} ROCK SPOILS

During soil investigation works, rock cores were extracted from boreholes located at the pipe-jacking shafts along the fractured and highly weathered Tuang Formation in Kuching

190 City. The extracted rock cores revealed very low RQD values. Ong and Choo (2011) reported similar observations during rock coring for a separate project sited also in the Tuang Formation. Thus, the use of reconstituted tunneling rock spoils for the development of strength parameters was examined. Such work has been conducted by Choo and Ong (2015).

194 Samples of tunneling rock spoils were sourced from pipe-jacking sites in Kuching City, which traversed sandstone, phyllite, and shale. Tunneling rock spoils were collected from decantation chambers, which screened slurry for coarser crushed spoils. The tunneling rock 
198 (MTBM), and subsequent crushing in the crushing cone of the MTBM. Preparation of 199 specimens for direct shear testing required the removal (or scalping) of grains with sizes 200 exceeding a tenth of the thickness of the test specimen (Head, 1992).

201 The scalped tunneling rock spoils were subjected to strain-controlled drained direct shear 202 tests in accordance with ASTM D 3080 (2003) and AS 1289.6.2.2 (1998). The fully 203 automated GeoComp ShearTrac II direct shear system was used to conduct the consolidation 204 and shearing of scalped tunneling rock spoils. Full automation of the test ensured reliability 205 of the tests, and a high resolution of monitored parameters, including shear stresses, shear 206 deformations, and vertical deformations.

207 Choo and Ong (2015) highlighted the nonlinearity of the shear strength of reconstituted 208 tunneling rock spoils. Hence, a simple power law function was adopted to capture the 209 nonlinearity of the test data (De Mello, 1977)

$210 \tau=A \cdot\left(\sigma^{\prime}\right)^{B}$

211 where $A$ and $B$ are constants. However, the jacking force model (see Eq. (1)) and the

212 estimation of vertical stresses due to arching (see Eq. (3)) still required the use of MC 213 parameters. Thus, the "generalized tangential" method was used to develop MC parameters 214 from the nonlinear data obtained from direct shear tests (Yang and Yin, 2004). The direct 215 shear test results and interpretation of tangential MC parameters are shown in Fig. 1.

\section{BACK-ANALYSES OF PIPE-JACKING FORCES}

217 Three underground pipe-jacking drives were studied and analyzed by Choo and Ong 218 (2015). The drives traversed through lithological units of sandstone, phyllite, and shale at 219 various depths. By applying the "generalized tangential" technique on earlier direct shear 220 testing of tunneling rock spoils, MC parameters were derived for the back-analysis of 221 frictional coefficient, $\mu_{a v g}$ in the studied drives using Eqs. (1) \& (3). A comparison was 222 conducted of the back-analyzed $\mu_{\text {avg }}$ against recommended values for lubricated drives, i.e. $\mu$ 
$223=0.1-0.3$ (Stein et al., 1989). The parameters used for back-analysis of the studied drives are presented in Table 1, with the measured jacking forces and resulting back-analyzed $\mu_{\text {avg }}$ shown in Figs. 2, 3 \& 4 for Drives A, B \& C respectively.

The jacking of Drive A encountered lithological units of sandstone, during which the average measured jacking force, $J F_{\text {meas }}$ was $14.4 \mathrm{kN} / \mathrm{m}$ (see Table 1). The MC parameters applied to the surrounding rock mass (Eq. (3)) were $C=c^{\prime}{ }_{p}=50.8 \mathrm{kPa}$ and $\phi=\phi^{\prime}{ }_{p}=47.8^{\circ}$. These values were derived from the tangent to the nonlinear function, applied at the effective overburden pressure indicative of the depth of the pipeline. Subsequently, the calculated $\sigma_{E V}$ (Eq. (3)) was $-20.8 \mathrm{kN} / \mathrm{m}^{2}$, indicating a strong occurrence of arching. For the purpose of the back-analysis, negative values of $\sigma_{E V}$ were adjusted to zero, since negative values would imply tensile stresses acting on the pipe crown, which is impossible due to the large overburden pressure. The amount of lubrication injected in the overcut was measured to be $47 \mathrm{~L} / \mathrm{m}$. As discussed in Choo and Ong (2015), comparison of the amount of injected lubricant against the theoretical overcut volume $(87 \mathrm{~L} / \mathrm{m})$ suggests that this drive was not well-lubricated, thus justifying the back-analyzed $\mu_{\text {avg }}$ of 0.315 . This value was at the upper limit of the suggested frictional coefficient for lubricated drives. Despite the reduced volume of injected lubricant, significant arching had reduced the normal soil stresses on the pipe, mitigating further accrual of jacking forces.

For Drive B, the propulsion of the jacked pipeline through phyllite formations resulted in average measured jacking forces of $4.8 \mathrm{kN} / \mathrm{m}$ (see Table 1). From the direct shear tests on reconstituted phyllite spoils (i.e. $C=57.8 \mathrm{kPa}$ and $\phi=44.3^{\circ}$ ), the calculated $\sigma_{E V}$ was -22.3

$244 \mathrm{kN} / \mathrm{m}^{2}$ (Choo and Ong, 2015). Similar to Drive A, the calculated $\sigma_{E V}$ implied a high degree of arching over the pipe-jacking drive. Subsequently, the back-analyzed $\mu_{\text {avg }}$ was 0.068 , suggesting the drive through phyllite was well-lubricated. This was verified by the high volumes of injected lubricant utilized for this drive, at $181 \mathrm{~L} / \mathrm{m}$ compared to a theoretical 
overcut volume of $113 \mathrm{~L} / \mathrm{m}$. The saturation of the overcut region with lubricant ensured a discrete lubricating layer, allowing for the reduction of rock-pipe interface shear stresses, and the suspension of the jacked pipeline within the bored tunnel. Suspension of the jacked pipeline reduced the rock-pipe contact area, thus further reducing jacking forces.

For Drive $\mathrm{C}$ in shale, the average measured jacking forces were $81.1 \mathrm{kN} / \mathrm{m}$ (see Table 1), which were the highest jacking forces observed among the studied drives. The estimation of vertical stresses on the pipe crown resulted in a $\sigma_{E V}$ of $11.7 \mathrm{kN} / \mathrm{m}^{2}$ (Choo and Ong, 2015). In comparison with Drives A \& B, this implied a reduced degree of arching acting on the outer peripheral of the jacked pipeline. Measurements of the injected lubricant at $729 \mathrm{~L} / \mathrm{m}$ far exceeded the theoretical overcut volume of $113 \mathrm{~L} / \mathrm{m}$. However, unlike Drive B, the excessive injection of lubricant indicated a significant loss of lubricant into the surrounding rock mass. This loss of lubricant suggested that the water tightness of the overcut region had been compromised, thus mitigating any lubricating and buoyancy effects, and increasing the jacking forces. This was verified by the back-analyzed $\mu_{\text {avg }}$ of 0.713 . Coupled with the reduced arching, the back-analyzed $\mu_{\text {avg }}$ was significantly higher than those for Drives A \& B.

The back-analyses of jacking forces based on the strength parameters obtained from the direct shear tests on reconstituted tunneling rock spoils have been conducted. The direct shear test results have been used to assess the measured jacking forces, in relation to arching

267 phenomenon and lubrication use. As shown in Figs. 2, 3, and 4, the reliable outcomes of the 268 back-analyses of jacking forces have successfully demonstrated the value in performing 269 direct shear tests using tunneling rock spoils in the absence of in-situ rock strengths. The application of the direct shear test results is conducted hereinafter, through the use of $3 \mathrm{D}$

271 finite element analysis. 


\section{NUMERICAL ANALYSES OF PIPE-JACKING FORCES}

3D finite element analysis was conducted to study the accrual of rock-pipe interface shear stresses through the simulation of typical spans along the studied drives. The analysis was performed using PLAXIS 3D, a commercially available finite element software package developed specifically for 3D analyses (Plaxis bv, 2013).

\subsection{Finite element mesh}

The finite element model used to simulate the observed pipe-jacking drives was $30 \mathrm{~m}$ wide ( $x$-direction transverse to pipeline), $20 \mathrm{~m}$ long ( $y$-direction longitudinal to pipeline) and $30 \mathrm{~m}$ deep ( $z$-direction), as shown in Fig. 5. The rock and soil masses were modeled using 10-node tetrahedral elements, with the pipeline modeled using 6-node plate elements. 12-node interface elements were used to model rock-pipe interaction. Standard fixity conditions were applied to the boundaries. Full fixity was applied to the bottom face to restrain movements in all directions, with rollers applied to the vertical faces to restrain movements in the horizontal plane.

\subsection{Rock properties}

The rock masses in the studied drives were assigned an elastic-perfectly plastic constitutive model, utilizing the MC failure criterion. It is recognized that other improved models are available for modeling of rock masses, such as the nonlinear Hoek-Brown failure criterion. However, the MC failure criterion was chosen to allow for parity with the stipulated MC parameters required for back-analyses of jacking forces (Pellet-Beaucour and Kastner, 2002) (Eqs. $1 \& 3$ ). Earlier interpretation of direct shear testing had acknowledged the nonlinearity of the shear strength for the tested tunneling rock spoils. Using the 'generalized tangential' technique (Yang and Yin, 2004), it was possible to express the nonlinear test results in terms of equivalent linear MC parameters, $c^{\prime}{ }_{p}$ and $\phi_{p}{ }_{p}$. These parameters were used 
to model the rock mass, where $c^{\prime}=c^{\prime}{ }_{p}$ and $\phi^{\prime}=\phi^{\prime}{ }_{p}$. The stiffness of the modeled rock masses were based on the findings of Bieniawski (1989),

$298 E_{M}=10^{(\mathrm{RMR}-10) / 40}$

300 where $E_{M}$ is the stiffness of the rock mass; RMR is the rock mass rating (Bieniawski, 1979); and $Q$ is the rock mass quality, which is a function of various rock joint properties including RQD (Barton et al., 1974). Due to the highly weathered nature of the geology along the studied drives, an RQD value of zero was assumed. This resulted in a rock modulus value of 7.1 GPa (see Tables $2,3 \& 4$ ).

In Eq. (3), Pellet-Beaucour and Kastner (2002) assumed constant isotropic conditions ( $K=$ 1 and $K_{0}=1$ ) for the soil above the tunnel. Hence, isotropic conditions were maintained for the numerical analyses conducted hereinafter to allow for a comparable simulation against the back-analyzed jacking forces.

\subsection{Pipeline, and rock-pipe interface properties}

310 The diameters of the modeled concrete pipelines are given in Table 1. The modeled

311 pipelines were $20 \mathrm{~m}$ long in the $y$-direction, and penetrated the finite element model, where

312 both ends of the modeled pipelines were flushed with the vertical model boundaries. Fixities

313 at the front end of the pipelines were subsequently released to allow for longitudinal

314 displacements of the pipeline, which was simulated by applying displacements at the tail ends 315 of the pipelines. The concrete pipelines were regarded as rigid bodies by artificially 316 increasing its elastic modulus. This was reasonable as the concrete pipeline has high stiffness 317 relative to the surrounding rock-pipe interface (Tian et al., 2014; Wang, D et al., 2009; Zhang 318 et al., 2013). The rigid pipeline would facilitate the segregation of the stresses due to pipe 319 compression from the jacking forces. 

modulus, $E^{\prime \prime}=1 \mathrm{kPa}$ for sliding failure associated with the deformation of a soil-structure interface. The low value of $E$ " was assigned so as to simulate separation of the interface when subjected to tensile stresses. A similarly low value of tangential interface modulus, $E_{t}=$ $17.4 \mathrm{kPa}$ was used for a study of interface elements in pull-out tests which underwent large shear deformations (Wang, $\mathrm{X}$ and Wang, 2006). For the rock-pipe interface elements used in this study, a similarly low value of interface modulus, $E_{\text {inter }}=1,000 \mathrm{kPa}$ was used.

$\phi_{i}=\tan ^{-1}\left(\mu_{\text {avg }}\right)$

330 given that $\tau_{i}$ is the rock-pipe interface shear strength; $\sigma_{n}{ }_{n}$ is the effective normal stress acting

331 on the rock-pipe interface; $\phi_{i}$ is the interface friction angle; and $\mu_{\text {avg }}$ is the back-analyzed average frictional coefficient, obtained from earlier back-analyses of jacking forces. The material properties in the respective drives for soil, rock, rock-pipe interface and pipeline are shown in Tables 2, 3 and 4.

\subsection{Modeling of pipe-jacking process}

336 All drives were modeled in three stages:

337 Stage 1 - Application of initial stress conditions.

338 Stage 2 - Wish-in-place pipeline, and activation of rock-pipe interface elements.

339 Stage 3 - Application of displacements at tail-end of pipeline.

340 In Stage 1 the generation of initial greenfield stress conditions was performed through the assignment of soil material properties, groundwater levels, $K_{0}$ condition, and model boundary deactivated. 

had already been installed into the block of elements, thus ignoring any installation effects.

The soil elements within the pipeline were deactivated at this stage. Water conditions within the pipeline were also set to dry, removing the effects of hydrostatic pressure within the void pipeline. Subsequently rock-pipe interface elements were activated.

Techniques for modeling of tunnels include the deactivation of unsupported soil elements (Chen et al., 2011), or the volume loss control method through the prescription of surface contraction along the modeled pipeline (Potts and Zdravković, 2001). Such techniques are typically applicable to the excavation of NATM tunnels, or large diameter mechanized tunneling. When these modeling methods are applied to the simulation of pipe-jacking drives, the convergence issues are often encountered particularly due to the high deformations of the interface elements. Hence, it was proposed for the pipeline to be 'wished-in-place' in order to negate convergence issues. The effects of arching would be considered subsequently, when the finite element modeling results are being analyzed in detail.

In Stage 3 horizontal ( $y$-direction) displacements were applied at the tail end of the pipeline. Fixities at the front end of the pipeline were released by introducing displacements along the periphery of the plate elements at the front. This was done to facilitate movement of the pipe beyond the boundaries of the soil block.

\subsection{Analysis of results from numerical simulation}

The displacements of plate elements representing the pipeline are shown in Fig. 6. All pipeline elements in the three simulated drives were displaced uniformly by $100 \mathrm{~mm}$ in the $y$ direction through the prescription of displacements at the tail end of the pipe. The exaggeration of pipe stiffness allowed for the modeled pipeline to be displaced evenly, mitigating any effects of pipe compression on the rock-pipe interface shear stresses. The 
Fig. 8 shows the distribution of interface shear stresses for Drive B, with similar observations made for Drives A \& C. The distribution of interface shear stresses, $\tau_{1}$ was uniform along the

371 longitudinal cross-section of the modeled pipeline, with the exception of interface elements at

372 the ends of the pipeline. This was due to end effects, resulting from the discontinuity of 373 interface and soil elements at the pipe ends (Plaxis bv, 2013). Radial distributions of $\tau_{1}$ at the 374 cross-section of the pipeline taken at mid-span of the pipeline were also uniform for all simulated drives. Fig. 9 shows the radial distribution of $\tau_{1}$ for Drive B, with similarly uniform distributions observed for Drives A \& C. This demonstrates the consistency of the finite element modeling technique.

Aside from the pipe ends, the uniformity of interface shear stresses elsewhere indicated that all interface elements had reached plasticity. Plasticity is significant in the modeling of pipe-jacking works as most jacking force predictive models assume no change in frictional resistance with displacement when tunneling through homogeneous geological conditions. Plasticity of the interface stresses can be verified using the appropriate overburden pressure acting on the pipe crown, with the back-analyzed frictional coefficient, $\mu_{\text {avg }}$ (see Eqs. 11 \& 12).

With the reliability of the finite element modeling technique developed herein, the issue of considering arching effects remains to be addressed. The pipe-jacking force model established by Pellet-Beaucour and Kastner (2002) relies on the effect of arching in order to determine the vertical stresses acting on the pipe crown, $\sigma_{E V}$ (see Eq. (3)). Arching reduces the soil stresses acting normal to the peripheral of the pipe crown, thus reducing the frictional interface shear stresses. This reduction in rock-pipe interface shear stresses due to arching can

391 be reflected by applying an appropriate arching ratio to the interface shear stresses, $\tau_{1}$ 392 computed from the earlier finite element modeling. For pipe-jacking works, the arching ratio 393 can be expressed as the change in soil stresses due to tunneling in relation to the total 
overburden pressure (see Eq. 7). By considering the pipe-jacking force model (see Eqs. (1) \&

395 (3)), the arching ratio, $A R$ is re-expressed and proposed to be

$396 \quad A R(\%)=\frac{\sigma_{E V}+\frac{\gamma D_{e}}{2}}{\gamma\left(h+\frac{D_{e}}{2}\right)} \times 100$

The arching ratio given in Eq. (13) was applied to the post-processing of interface shear stresses obtained from the numerical modeling, with the calculated jacking forces, $J F_{\tau, c a l}$ given as

400

$J F_{\tau, c a l}=A R \times \tau_{1} \pi D_{e}$

where $\tau_{1}$ is the interface shear stress tangential to the direction of displacement ( $y$-direction).

The resulting calculated jacking forces for the studied drives are shown in Table 5, and were subsequently compared against the respective measured jacking forces, $J F_{\text {meas }}$. This shows reasonable agreement between the calculated jacking forces from numerical modeling against the jacking forces measured in-situ, i.e. error of between $15 \%$ and $25 \%$. Further verification was conducted by examining the reaction forces on the prescribed displacements, given that

$407 \quad J F_{F y, c a l}=A R \times \frac{\sum F_{y}}{L}$

where $J F_{F y, c a l}$ is the jacking force calculated from reaction forces; $\Sigma F_{y}$ is the reaction force on prescribed displacements; and $L$ is the pipe length. The jacking forces, $J F_{F y, c a l}$ derived from the reaction force, $\Sigma F_{y}$ were also in reasonable agreement with the average measured jacking

411 forces, $J F_{\text {meas }}($ see Table 5).

412 For each modeled drive, the stress fields were statically admissible since the reaction 413 forces, $\Sigma F_{y}$ were in equilibrium with the interface shear stresses, $\tau_{1}$ integrated along the outer 414 surface area of the modeled pipeline (see Table 5). This state of equilibrium was achieved 415 with the elastic-perfectly plastic MC failure criterion adopted for the interface elements, 416 where the yield criterion was not exceeded. Hence, the solutions resulting from finite element 
417 modeling are considered lower bound. During tunneling, the traversed geology was crushed

418 into tunneling rock spoils, resulting in the significant loss of cementation in rock mass.

419 Hence, the use of strength parameters obtained from testing on the tunneling rock spoils

420 further reinforces that the results from finite element modeling were lower bound solutions.

421 This resulted in the underestimation of measured jacking forces obtained from the finite 422 element modeling. This underestimation of measured jacking forces could also have been 423 attributed to the assumption of average uniform conditions along the studied drives, such as 424 lubrication and rock-pipe contact across the modeled drive. However, this assumption was 425 necessary in order to draw parity with the jacking force model (Eqs. 1 \& 3), which considers 426 jacking forces to be uniform along homogenous geological conditions. In reality, the 427 distribution of lubrication and rock-pipe contact are expected to fluctuate, resulting in 428 variations of jacking forces (see Figs. 2, 3 \& 4) (Marshall and Milligan, 1996).

429 Direct shear test results, $c_{p}^{\prime} \& \phi_{p}^{\prime}$ and back-analyzed frictional coefficient, $\mu_{a v g}$ have been 430 successfully applied to three pipe-jacking drives. The application of these parameters has also 431 been conducted using 3D finite element modeling technique to assess the reliability of these 432 parameters for the assessment of pipe-jacking forces through the highly fractured and 433 weathered geology of the Tuang Formation in Kuching City, Malaysia. The jacking forces derived from numerical modeling have shown reasonable agreement with the measured jacking forces, demonstrating the reliability in using the tangential strength parameters 436 developed from direct shear tests on reconstituted tunneling rock spoils.

\section{5. CONCLUSIONS}

A novel approach was proposed for the assessment of pipe-jacking forces in highly weathered and fractured geology, involving the reconstitution of tunneling rock spoils for

440 direct shear testing. The tunneling spoils were assessed for geotechnical strength properties using a "generalized tangential" technique to allow for the application of the nonlinear test 
results to a well-established jacking force model (Pellet-Beaucour and Kastner, 2002), which

443 requires the use of linear elastic-perfectly plastic MC strength parameters, i.e. $c_{p}^{\prime}$ and $\phi_{p}$.

444 Back-analyses of the jacking forces using the tangential MC strength parameters have been 445 successfully executed, resulting in the development of $\mu_{\text {avg }}$ for the three drives, i.e. $\mu_{\text {avg }}=$ 4460.315 (not well-lubricated) for Drive A in sandstone, $\mu_{\text {avg }}=0.068$ (well-lubricated) for Drive $447 \mathrm{~B}$ in phyllite, and $\mu_{\text {avg }}=0.713$ (loss of lubrication resulting in high friction) for Drive $\mathrm{C}$ in 448 shale.

449 Further validation of $c_{p}{ }_{p}, \phi_{p}{ }_{p}$ and $\mu_{a v g}$ was conducted through $3 \mathrm{D}$ finite element modeling 450 technique of the three pipe-jacking drives. Strength parameters $c_{p}{ }_{p}$ and $\phi^{\prime}{ }_{p}$ were applied to the 451 model rock mass, while the back-analyzed $\mu_{\text {avg }}$ was applied to the failure criteria of the rock452 pipe interface elements. The modeled concrete pipelines were wished-in-place, with the effects of arching considered during post-processing of the results through the use of a proposed arching ratio. The proposed arching ratio was applied to the resulting rock-pipe interface shear stresses and reaction forces calculated from the finite element modeling results, which demonstrated reasonable agreement between the corresponding predicted and measured jacking forces.

These results have demonstrated the consistency and reliability of the results from reconstituted tunneling rock spoils tested in the direct shear apparatus. This allows for potential prediction of pipe-jacking forces through weathered geological formations by using

461 the direct shear test on reconstituted tunneling rock spoils for future pipe-jacking works in the 462 subsequent phases of the project.

\section{ACKNOWLEDGMENT}

464 The financial support provided by Hock Seng Lee Bhd. and Jurutera Jasa (Sarawak) Sdn. 465 Bhd. is gratefully acknowledged. 


\section{REFERENCES}

467 Abbott, P. A. 1967, 'Arching for vertically buried prismatic structures', J. Soil Mech. Found. Div., 93 $468 \quad$ (5), pp. 233-55.

ASTM 2003, Standard Test Method for Direct Shear Test of Soils under Consolidated Drained Conditions, ASTM-D3080-03, West Conshohocken, PA.

Barla, M., Camusso, M. and Aiassa, S. 2006, 'Analysis of jacking forces during microtunnelling in limestone', Tunn. Undergr. Sp. Tech., 10.1016/j.tust.2006.01.002, 21 (6), pp. 668-83.

Barton, N., Lien, R. and Lunde, J. 1974, 'Engineering classification of rock masses for the design of tunnel support', Rock Mech., 10.1007/BF01239496, 6 (4), pp. 189-236.

Bieniawski, Z. T. 1979, 'Tunnel design by rock mass classifications', in US Army Corps of Engineers Technical Report GL-79-19, U.S. Waterways Experimental Station, Vicksburg.

Bieniawski, Z. T. 1989, Engineering rock mass classifications : a complete manual for engineers and geologists in mining, civil, and petroleum engineering, Wiley.

Borges, J. L. and Marques, D. O. 2011, 'Geosynthetic-reinforced and jet grout column-supported embankments on soft soils: Numerical analysis and parametric study', Comput. Geotech., 10.1016/j.compgeo.2011.06.003, 38 (7), pp. 883-96.

Chapman, D. N. and Ichioka, Y. 1999, 'Prediction of jacking forces for microtunnelling operations', Tunn. Undergr. Sp. Tech., 10.1016/S0886-7798(99)00019-X, 14 (1), pp. 31-41.

Chen, C. N., Huang, W.-Y. and Tseng, C.-T. 2011, 'Stress redistribution and ground arch development during tunneling', Tunn. Undergr. Sp. Tech., 10.1016/j.tust.2010.06.012, 26 (1), pp. $486 \quad 228-35$.

487 Choo, C. S. and Ong, D. E. L. 2012, 'Back-analysis of frictional jacking forces based on shear box 488 testing of excavated spoils', in Proc., 2nd Int. Conf. on Geotechnique, Construction Materials and Environment, GEOMATE International Society, Tsu, Mie, Japan, Kuala Lumpur, Malaysia, pp. $462-7$. 
Choo, C. S. and Ong, D. E. L. 2014, 'Assessment of pipe-jacking forces through direct shear tests on tunneling rock spoils', in Computer Methods and Recent Advances in Geomechanics, CRC Press, pp. 471-6, DOI 10.1201/b17435-79.

494

Choo, C. S. and Ong, D. E. L. 2015, 'Evaluation of pipe-jacking forces based on direct shear testing of reconstituted tunneling rock spoils', J. Geotech. Geoenviron. Eng., 10.1061/(ASCE)GT.19435606.0001348 .

De Mello, V. F. B. 1977, 'Reflections on design decisions of practical significance to embankment dams', Géotechnique, 10.1680/geot.1977.27.3.281, 27 (3), pp. 281-354.

Deb, K. 2010, 'A mathematical model to study the soil arching effect in stone column-supported embankment resting on soft foundation soil', Appl. Math. Model., 10.1016/j.apm.2010.03.026, 34 (12), pp. 3871-83.

French Society for Trenchless Technology 2006, Microtunneling and Horizontal Drilling : Ltd, London.

Han, J. and Gabr, M. 2002, 'Numerical Analysis of Geosynthetic-Reinforced and Pile-Supported Earth Platforms over Soft Soil', J. Geotech. Geoenviron. Eng., 10.1061/(ASCE)10900241(2002)128:1(44), 128 (1), pp. 44-53.

Head, K. H. 1992, Manual of soil laboratory testing. Vol. 2, Permeability, shear strength and compressibility tests, Halsted Press, New York.

Iscimen, M. 2004, 'Shearing behavior of curved interfaces', Master of Science thesis, Georgia Institute of Technology.

512 Kishida, H. and Uesugi, M. 1987, 'Tests of the interface between sand and steel in the simple shear apparatus', Géotechnique, 10.1680/geot.1987.37.1.45, 37 (1), pp. 45-52.

514 Lee, C. J., Wu, B. R., Chen, H. T. and Chiang, K. H. 2006, 'Tunnel stability and arching effects during tunneling in soft clayey soil', Tunn. Undergr. Sp. Tech., 10.1016/j.tust.2005.06.003, 21 (2), pp. 119-32.

517 Marshall, M. A. and Milligan, G. W. E. 1996, 'A case study of an instrumented microtunnel in fine 518 sand', in No-Dig 1996, New Orleans. 
McNulty, J. W. 1965, 'An experimental study of arching on sand', in US Army Corps of Engineers Technical Report I-674, U.S. Waterways Experimental Station, Vicksburg.

Ong, D. E. L. and Choo, C. S. 2011, 'Sustainable construction of a bored pile foundation system in erratic phyllite', ASEAN Australian Engineering Congress, Kuching, Malaysia, 25 - 27 July 2011.

Osumi, T. 2000, 'Calculating jacking forces for pipe jacking methods', No-Dig International Research, (October, 2000), pp. 40-2.

Pellet-Beaucour, A. L. and Kastner, R. 2002, 'Experimental and analytical study of friction forces during microtunneling operations', Tunn. Undergr. Sp. Tech., 10.1016/S0886-7798(01)00044-X, 17 (1), pp. 83-97.

Plaxis bv 2013, PLAXIS 3D 2013 Manual, Delft, The Netherlands.

Potts, D. M. and Zdravković, L. 2001, Finite element analysis in geotechnical engineering: application, vol. 2, Thomas Telford Services Limited.

Shou, K. J., Yen, J. and Liu, M. 2010, 'On the frictional property of lubricants and its impact on jacking force and soil-pipe interaction of pipe-jacking', Tunn. Undergr. Sp. Tech.,

$$
\text { 10.1016/j.tust.2010.02.009, } 25 \text { (4), pp. 469-77. }
$$

Sofianos, A. I., Loukas, P. and Chantzakos, C. 2004, 'Pipe jacking a sewer under Athens', Tunn. Undergr. Sp. Tech., 10.1016/S0886-7798(03)00108-1, 19 (2), pp. 193-203.

Staheli, K. 2006, 'Jacking force prediction an interface friction approach based on pipe surface roughness', PhD thesis, Georgia Institute of Technology, viewed 29 January 2010.

Standards Australia 1998, Soil strength and consolidation tests - Determination of the shear strength of a soil - Direct shear test using a shear box, Standards Australia, Australia, AS 1289.6.2.2-1998.

Stein, D., Möllers, K. and Bielecki, R. 1989, Microtunnelling : Installation and Renewal of NonmanSize Supply and Sewage Lines by the Trenchless Construction Method, Ernst, Berlin, Germany. Tan, D. N. K. 1993, Geology of the Kuching Area, West Sarawak, Malaysia, Geological Survey of Malaysia, Kuching, Malaysia.

Terzaghi, K. 1936, 'Stress distribution in dry and in saturated sand above a yielding trap-door', Proc., 1st Intl. Conf. on Soil Mechanics and Foundation Engineering, Graduate School of Engineering, Harvard Univ., Cambridge, Massachusetts, USA. 
547 Terzaghi, K. 1943, Theoretical soil mechanics, John Wiley \& Sons, Inc.

548 Tian, Y., Cassidy, M. J., Randolph, M. F., Wang, D. and Gaudin, C. 2014, 'A simple implementation 549 of RITSS and its application in large deformation analysis', Comput. Geotech.,

$550 \quad$ 10.1016/j.compgeo.2013.12.001, 56 pp. 160-7.

551 Wang, D., Hu, Y. and Randolph, M. F. 2009, 'Three-dimensional large deformation finite-element

552 analysis of plate anchors in uniform clay', J. Geotech. Geoenviron. Eng.,

553 10.1061/(ASCE)GT.1943-5606.0000210, 136 (2), pp. 355-65.

554 Wang, X. and Wang, L. B. 2006, 'Continuous interface elements subject to large shear deformations', 555 Int. J. Geomech., 10.1061/(ASCE)1532-3641(2006)6:2(97), 6 (2), pp. 97-107.

556 Yang, X. L. and Yin, J. H. 2004, 'Slope stability analysis with nonlinear failure criterion', J. Eng. $557 \quad$ Mech., 10.1061/(ASCE)0733-9399(2004)130:3(267), 130 (3), pp. 267-73.

558 Ye, G., Zhang, Z., Han, J., Xing, H., Huang, M. and Xiang, P. 2012, 'Performance Evaluation of an 559 Embankment on Soft Soil Improved by Deep Mixed Columns and Prefabricated Vertical Drains', $560 \quad$ J. Perform. Constr. Fac., 10.1061/(ASCE)CF.1943-5509.0000369, 27 (5), pp. 614-23.

561 Yin, Z.-Z., Zhu, H. and Xu, G.-H. 1995, 'A study of deformation in the interface between soil and 562 concrete', Comput. Geotech., 10.1016/0266-352X(95)91303-L, 17 (1), pp. 75-92.

563 Zhang, X., Krabbenhoft, K., Pedroso, D. M., Lyamin, A. V., Sheng, D., da Silva, M. V. and Wang, D. 5642013 , 'Particle finite element analysis of large deformation and granular flow problems', Comput. $565 \quad$ Geotech., 10.1016/j.compgeo.2013.07.001, 54 pp. 133-42. 


\begin{tabular}{|c|c|c|c|}
\hline & $\begin{array}{c}\text { Drive A } \\
\text { Sandstone }\end{array}$ & $\begin{array}{l}\text { Drive B } \\
\text { Phyllite }\end{array}$ & $\begin{array}{c}\text { Drive C } \\
\text { Shale }\end{array}$ \\
\hline 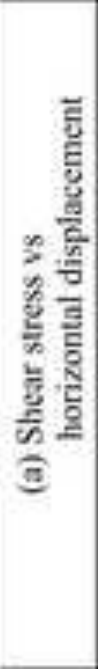 & 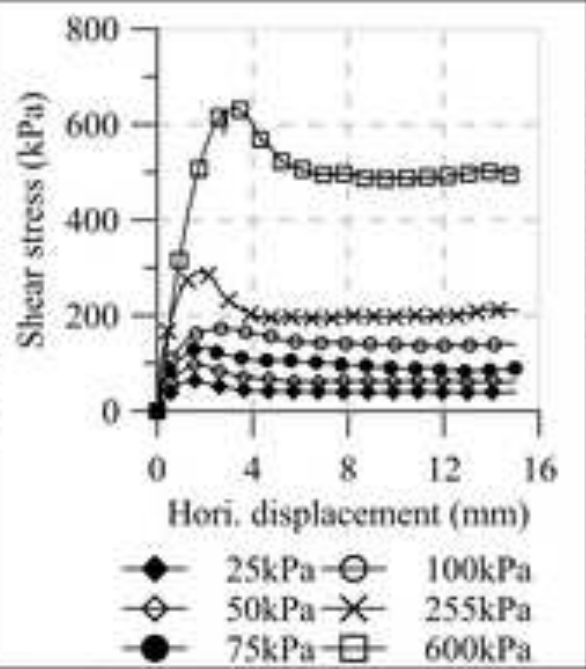 & $\begin{array}{l}5007 \\
0 \\
\text { Hori. displacement (mm) }\end{array}$ & Hori, displacement (mm) \\
\hline 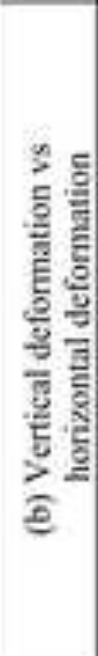 & 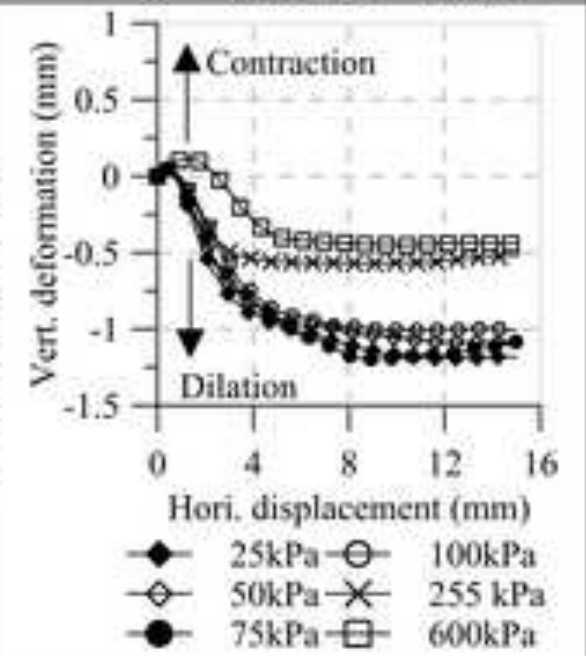 & 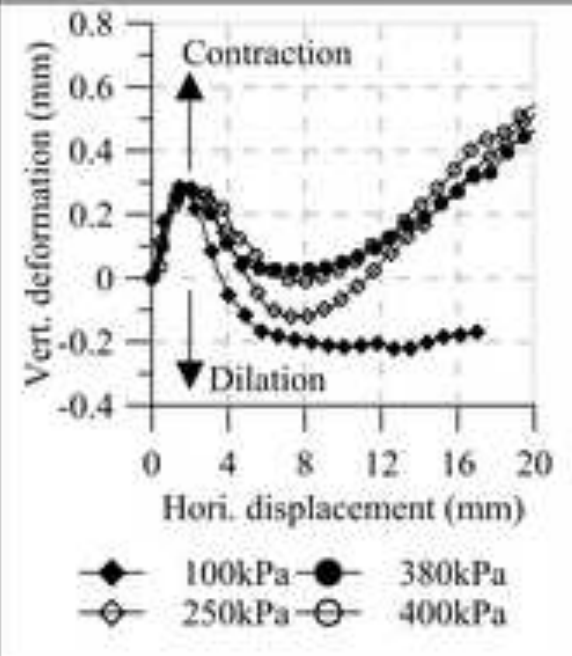 & 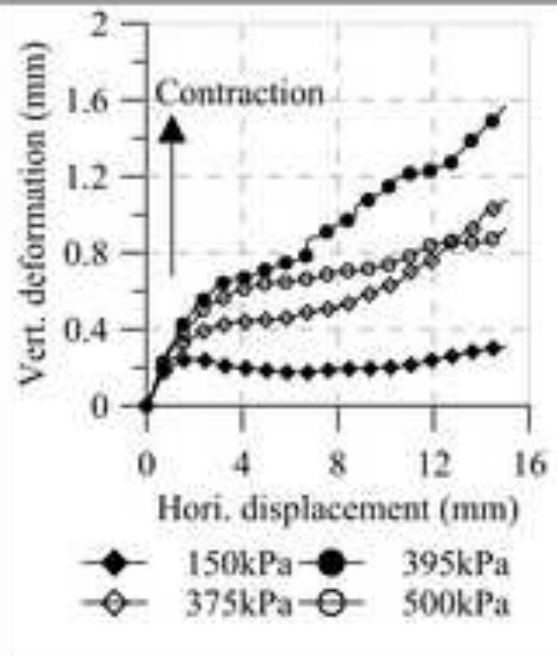 \\
\hline 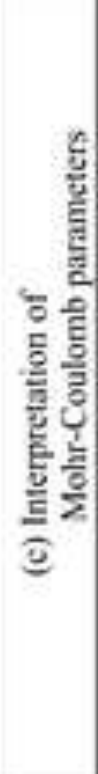 & 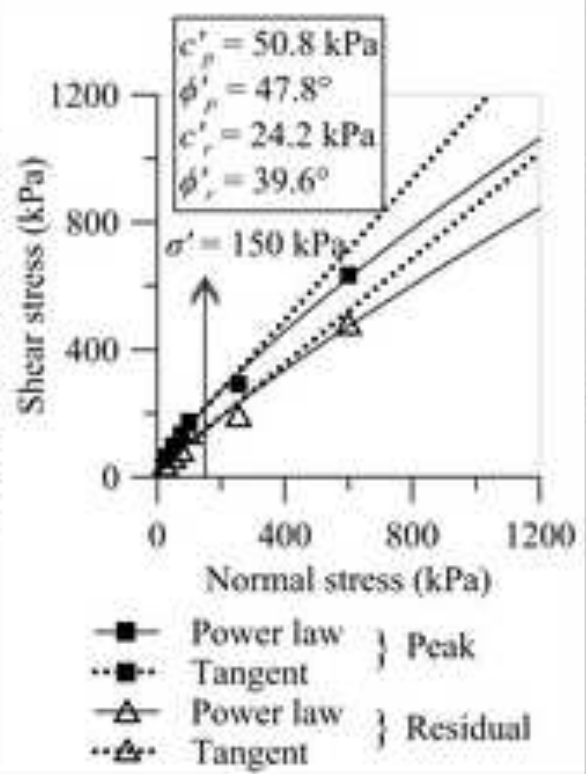 & 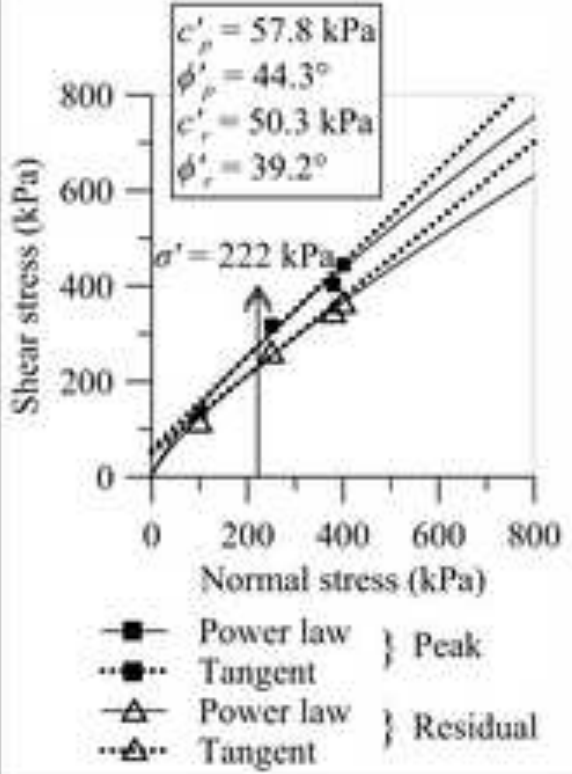 & 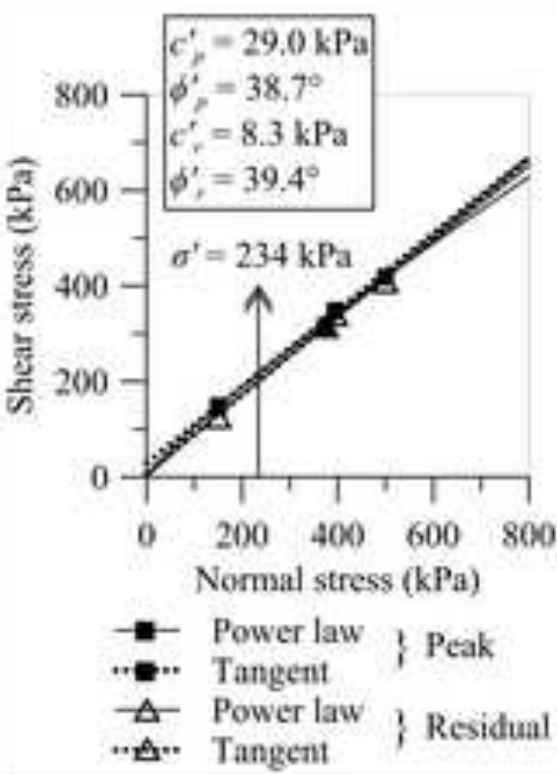 \\
\hline
\end{tabular}

Fig. 1. Results from direct shear testing of scalped tunneling rock spoils (Choo and Ong, 2014b) 


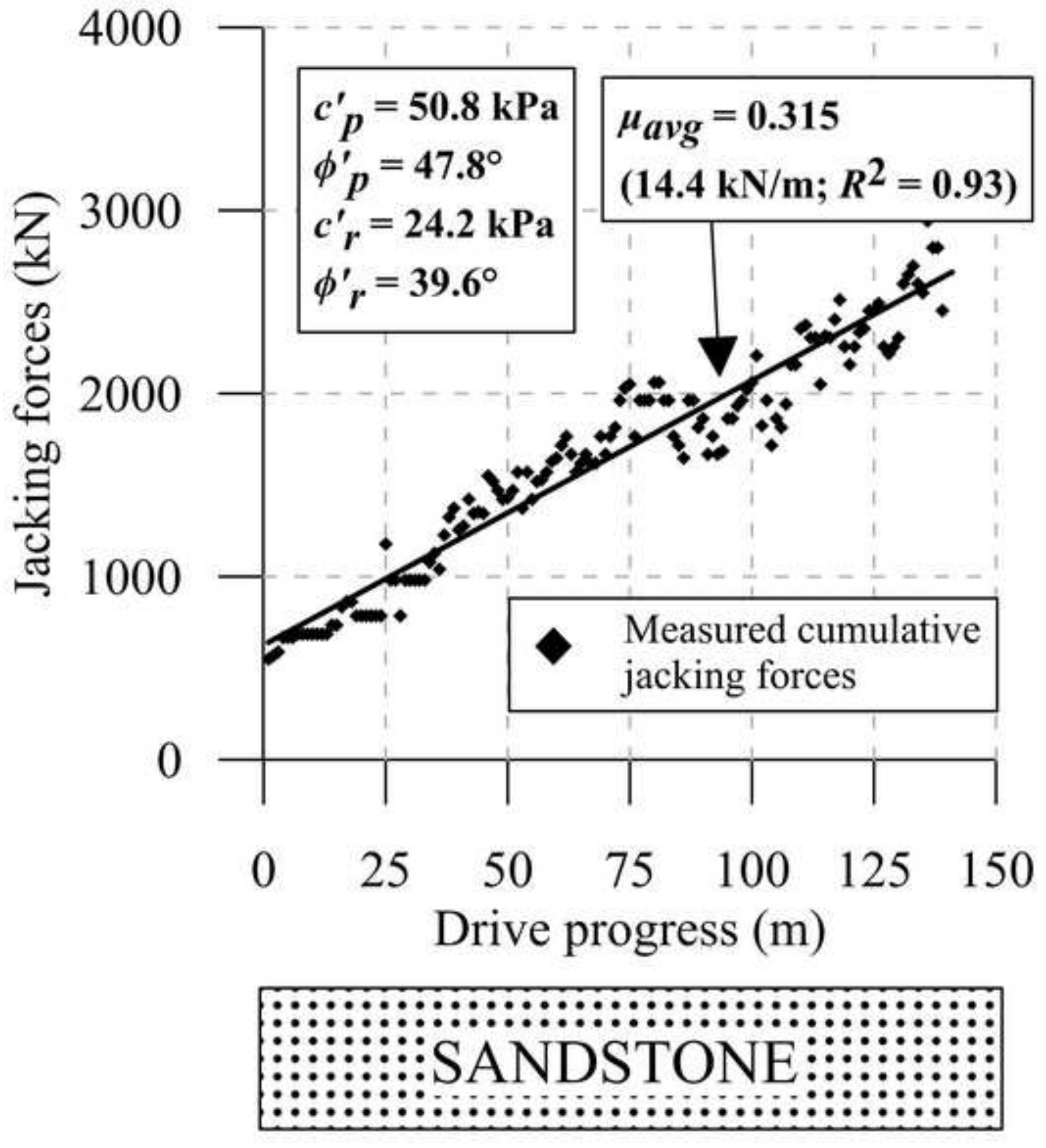

Fig. 2. Drive A: Outcome of back-analyzed $\mu_{\text {avg }}$ 

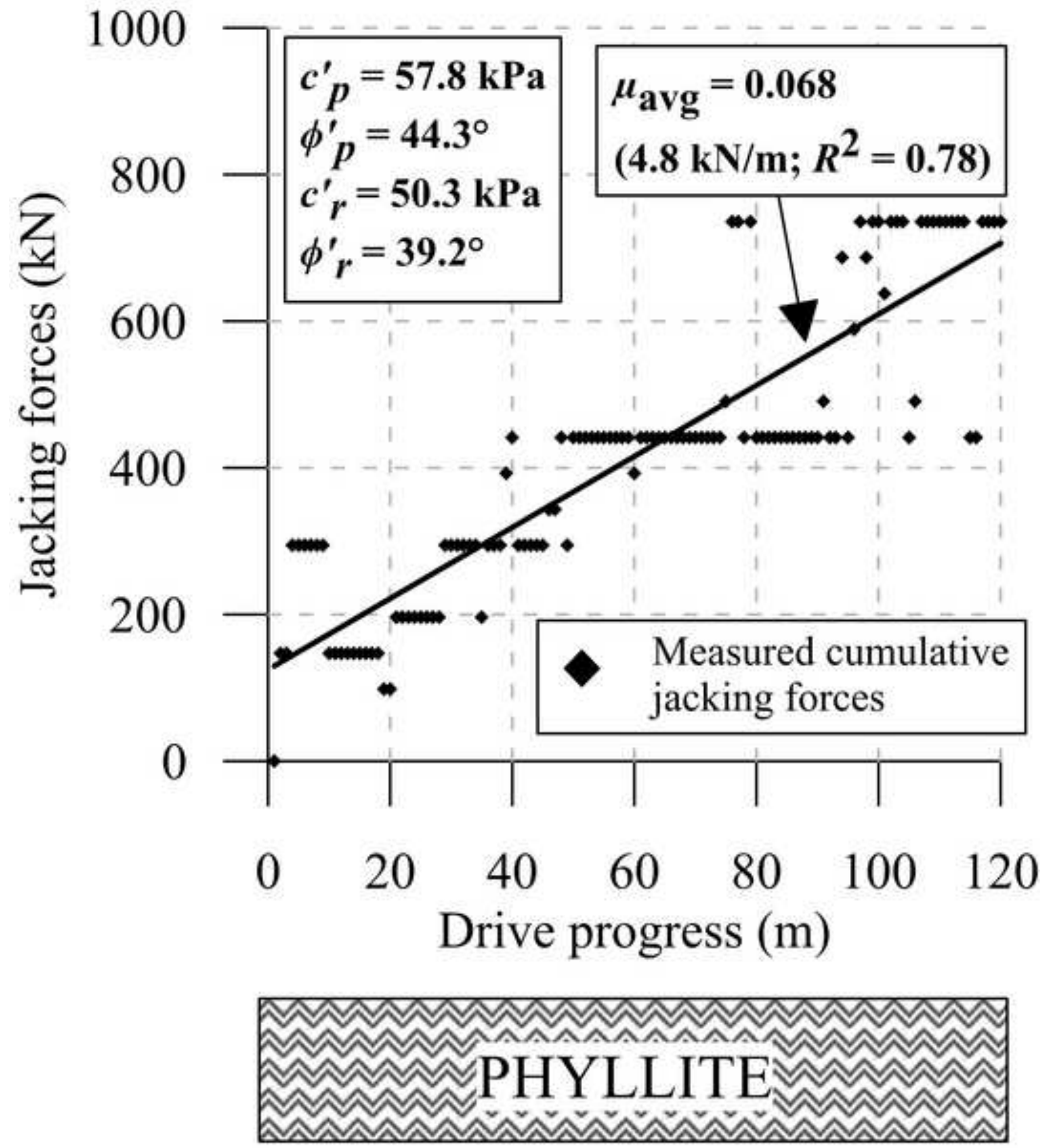

Fig. 3. Drive B: Outcome of back-analyzed $\mu_{\text {avg }}$ 

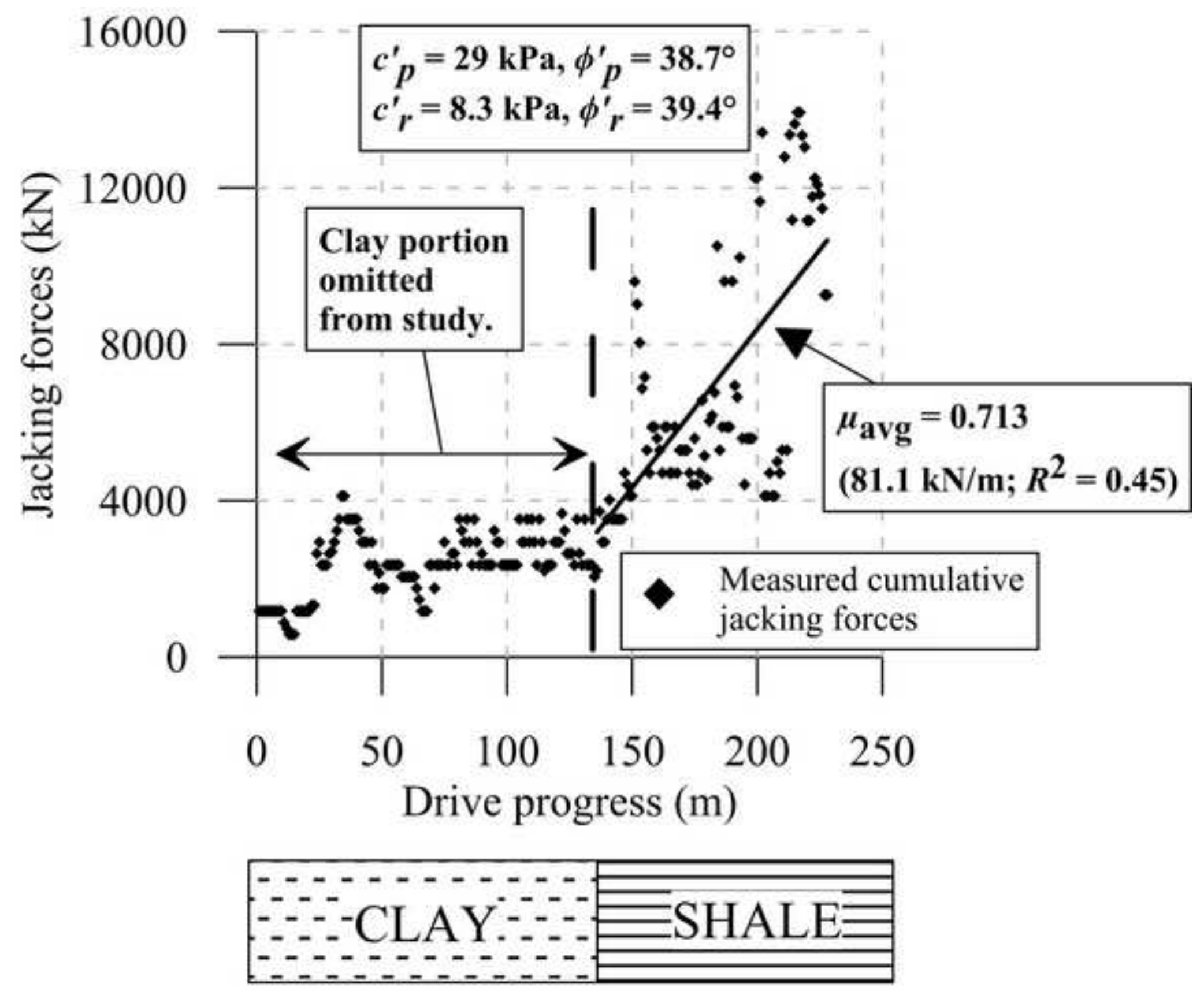

Fig. 4. Drive C: Outcome of back-analyzed $\mu_{\text {avg }}$ 
Figure 5

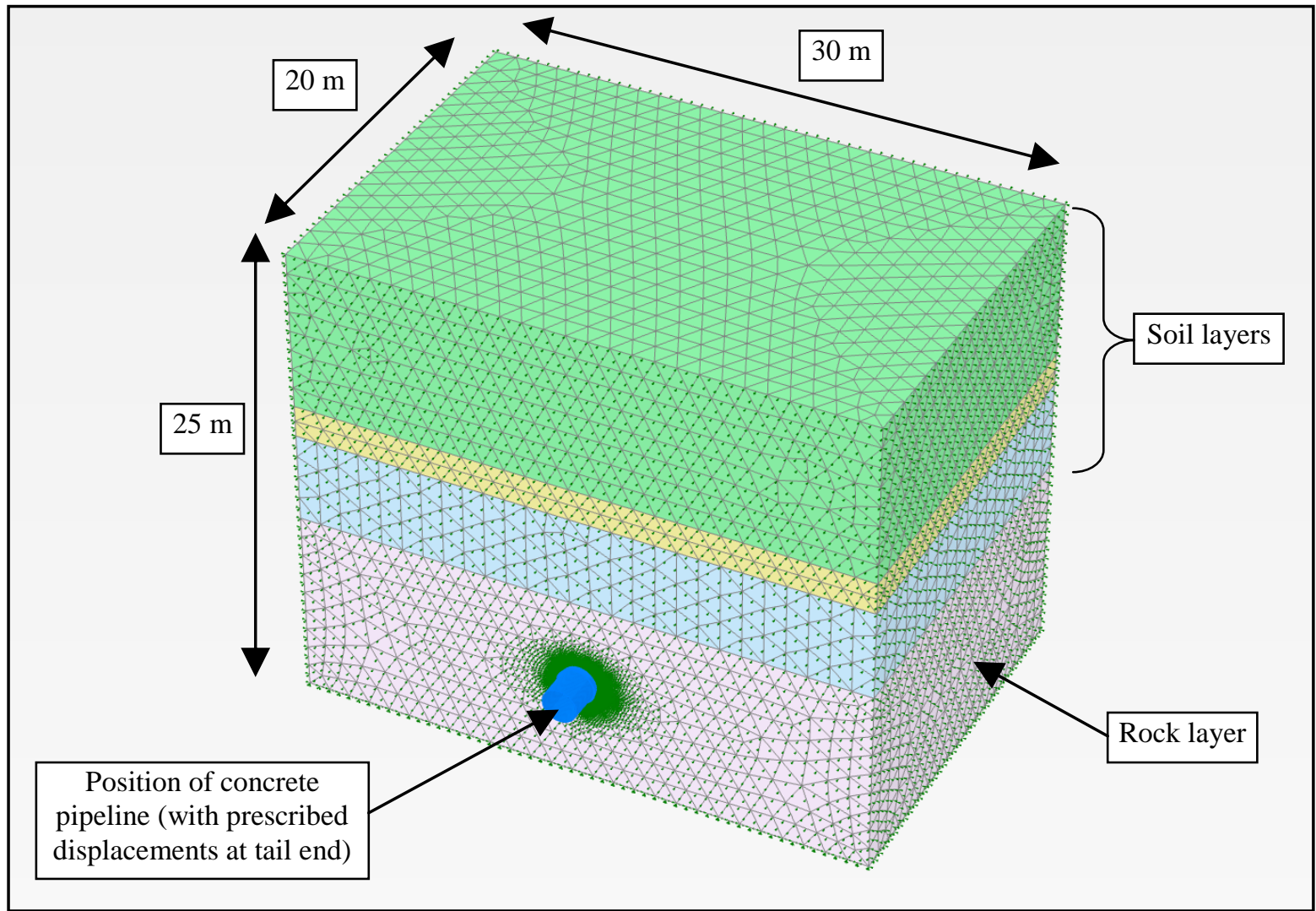

Fig. 5. Typical model used for numerical analysis of interface shear stresses (model for Drive

B shown above) 
Figure 6

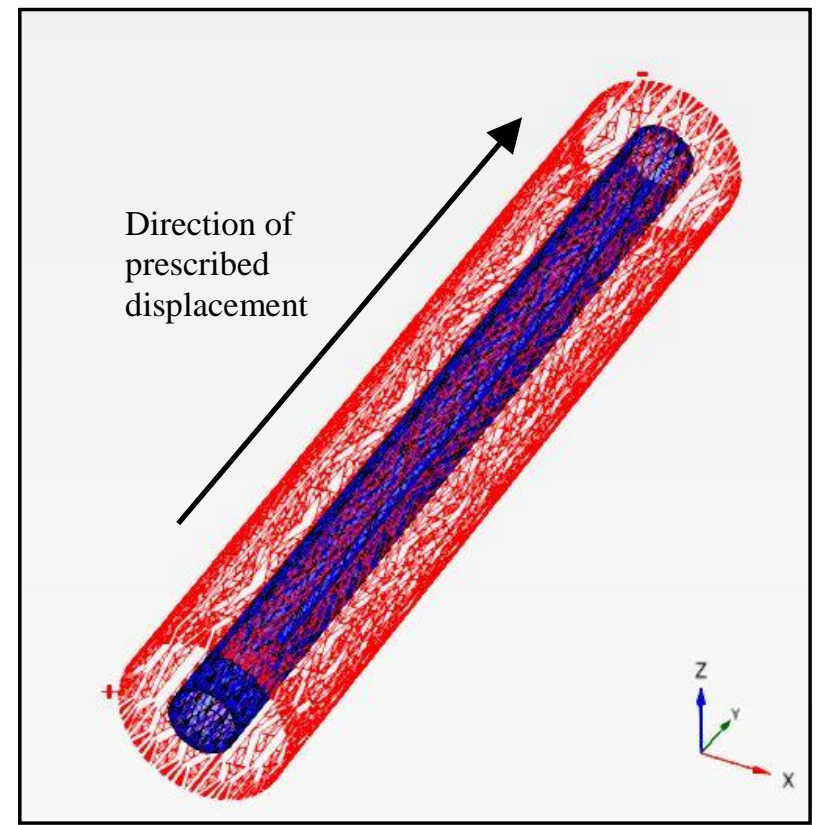

Fig. 6. Distribution of pipeline displacements after application of prescribed displacements 


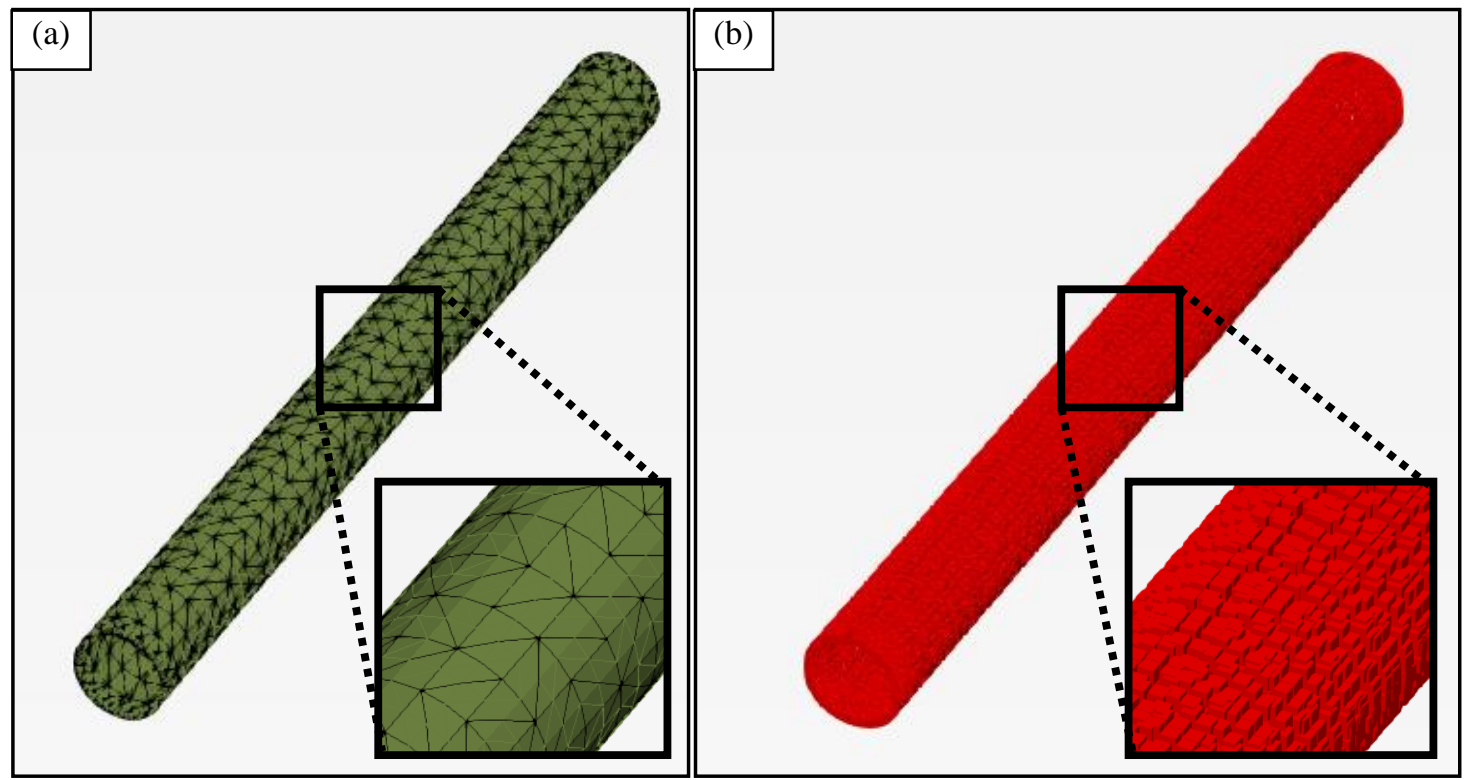

Fig. 7. (a) Absence of plastic interface elements before displacement, as indicated by mesh outline; (b) all interface elements achieve plasticity after displacement of $100 \mathrm{~mm}$, as indicated by blocks. 


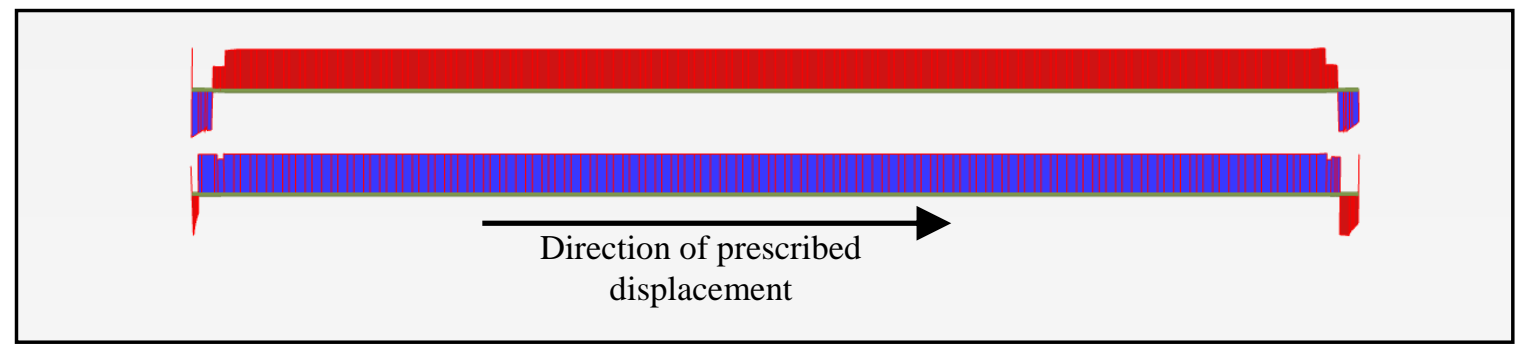

Fig. 8. Uniform distribution of interface shear stresses, $\tau_{1}$ along modeled pipeline (results for Drive B shown above) 


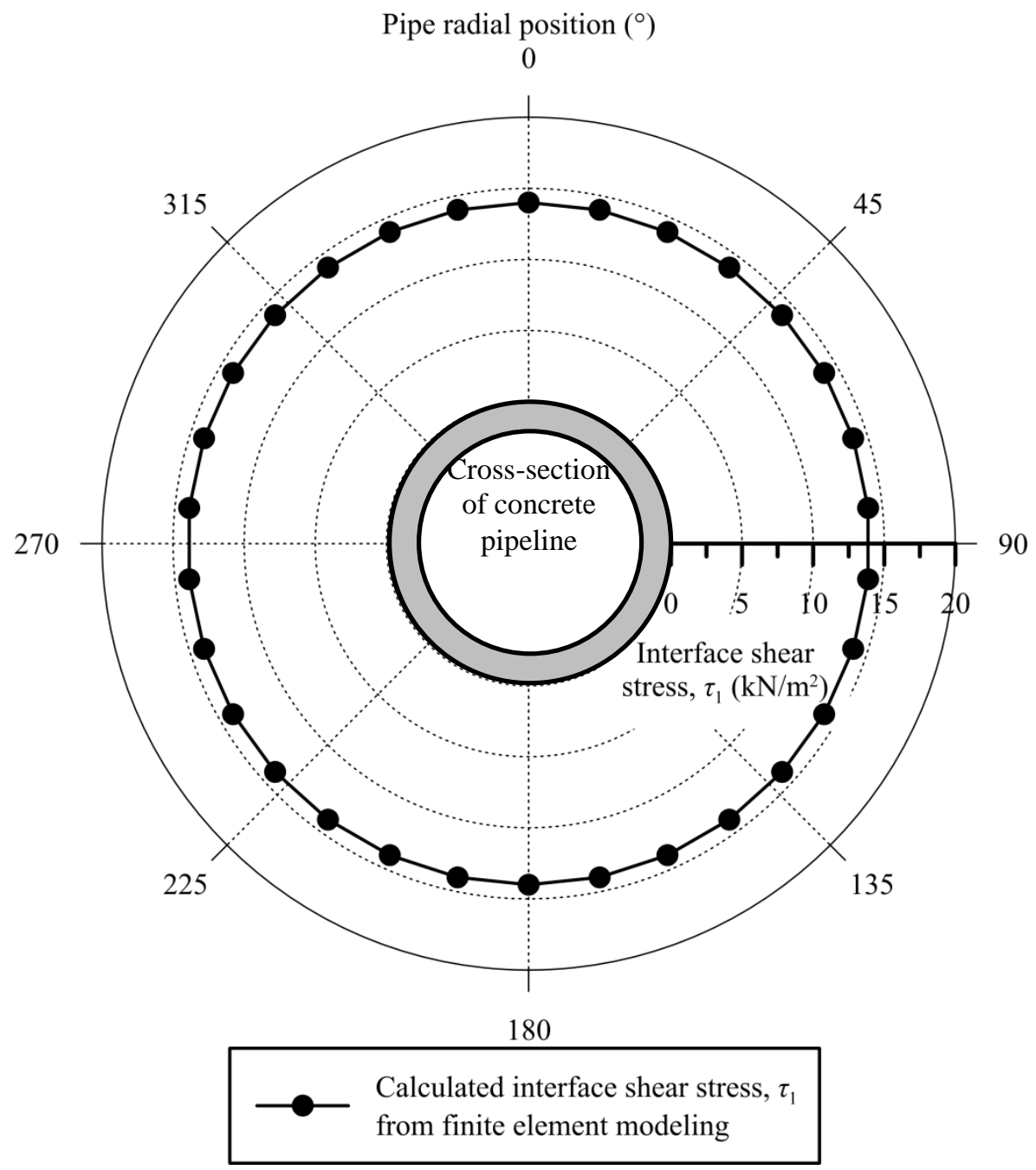

2 Fig. 9. Distribution of interface shear stresses, $\tau_{1}$ at mid-span of modeled pipeline (results for Drive B shown above) 
Table 1. Parameters used in pipe-jacking force model for back-analyses of $\mu_{\text {avg }}$ (Choo and Ong, 2014b)

\begin{tabular}{|c|c|c|c|c|}
\hline \multicolumn{2}{|l|}{$\begin{array}{l}\text { Drive } \\
\text { Geology }\end{array}$} & $\begin{array}{c}\text { Drive A } \\
\text { Sandstone }\end{array}$ & $\begin{array}{l}\text { Drive B } \\
\text { Phyllite }\end{array}$ & $\begin{array}{c}\text { Drive C } \\
\text { Shale }\end{array}$ \\
\hline \multicolumn{2}{|l|}{ External pipe diameter, $D_{e}(\mathrm{~m})$} & 1.43 & 1.78 & 1.78 \\
\hline \multicolumn{2}{|l|}{ Soil unit weight, $\gamma_{\text {soil }}\left(\mathrm{kN} / \mathrm{m}^{3}\right)$} & 18 & 18 & 18 \\
\hline \multicolumn{2}{|l|}{ Depth to rock level (m) } & 9.5 & 15.0 & 19.0 \\
\hline \multicolumn{2}{|l|}{ Rock unit weight, $\gamma_{\text {rock }}\left(\mathrm{kN} / \mathrm{m}^{3}\right)$} & 22 & 22 & 22 \\
\hline \multicolumn{2}{|l|}{ Height of rock cover $(\mathrm{m})$} & 3.0 & 3.5 & 0.5 \\
\hline $\begin{array}{l}\text { Tangential MC parameters obtained } \\
\text { from direct shear testing }\end{array}$ & $\begin{array}{l}c_{p}^{\prime}\left(\mathrm{kN} / \mathrm{m}^{2}\right) \\
\phi_{p}^{\prime}\left({ }^{\circ}\right)\end{array}$ & $\begin{array}{l}50.8 \\
47.8\end{array}$ & $\begin{array}{l}57.8 \\
44.3\end{array}$ & $\begin{array}{l}29.0 \\
38.7\end{array}$ \\
\hline \multirow{2}{*}{\multicolumn{2}{|c|}{$\begin{array}{l}\text { Average measured jacking forces, } J F_{\text {meas }}(\mathrm{kN} / \mathrm{m}) \\
\text { Vertical stress acting on pipe crown, } \sigma_{E V}\left(\mathrm{kN} / \mathrm{m}^{2}\right) \\
\text { (see Eq. 3) }\end{array}$}} & 14.4 & 4.8 & 81.1 \\
\hline & & -20.8 & -22.3 & 11.7 \\
\hline \multicolumn{2}{|l|}{$\begin{array}{l}\text { Back-analyzed } \mu_{\text {avg }} \text {, using Eq. (1) } \\
R^{2}\end{array}$} & $\begin{array}{c}0.315 \\
0.93\end{array}$ & $\begin{array}{c}0.068 \\
0.78\end{array}$ & $\begin{array}{c}0.713 \\
0.45\end{array}$ \\
\hline
\end{tabular}


Table 2. Material properties for finite element modeling of Drive A

\begin{tabular}{|c|c|c|c|c|c|c|}
\hline Material & $\begin{array}{l}\text { Stiff silty clay } \\
\quad \text { (SPT 10) }\end{array}$ & $\begin{array}{l}\text { Very stiff } \\
\text { silty clay } \\
\text { (SPT 22) }\end{array}$ & $\begin{array}{c}\text { Hard silty } \\
\text { clay (SPT 50) }\end{array}$ & Sandstone & $\begin{array}{l}\text { Rock-pipe } \\
\text { interface }\end{array}$ & Pipe \\
\hline $\begin{array}{l}\text { Elements } \\
\text { used }\end{array}$ & Soil & Soil & Soil & Soil & Interface & Plate \\
\hline $\begin{array}{l}\text { Material } \\
\text { model }\end{array}$ & $\mathrm{MC}$ & $\mathrm{MC}$ & $\mathrm{MC}$ & $\mathrm{MC}$ & $\mathrm{MC}$ & $\begin{array}{l}\text { Linear } \\
\text { elastic }\end{array}$ \\
\hline Depth (m) & 0 to 5.8 & 5.8 to 8.2 & 8.2 to 9.5 & 9.5 to 20 & - & - \\
\hline $\begin{array}{l}\text { Unit weight, } \gamma \\
\left(\mathrm{kN} / \mathrm{m}^{3}\right)\end{array}$ & 18 & 18 & 18 & 22 & - & 24 \\
\hline $\begin{array}{l}\text { Cohesion, } c^{\prime} \\
(\mathrm{kPa})\end{array}$ & 5 & 10 & 15 & $50.8^{\mathrm{a}}$ & 0 & - \\
\hline $\begin{array}{l}\text { Friction } \\
\text { angle, } \phi^{\prime}\left(^{\circ}\right)\end{array}$ & 28 & 28 & 30 & $47.8^{\mathrm{a}}$ & $20.05^{\mathrm{b}}$ & - \\
\hline $\begin{array}{l}\text { Elastic } \\
\text { modulus, } E^{\prime} \\
\left(\mathrm{kN} / \mathrm{m}^{2}\right)\end{array}$ & 11,000 & 24,200 & 55,000 & $7.1 \times 10^{6}$ & 1,000 & $27 \times 10^{9 c}$ \\
\hline $\begin{array}{l}\text { Poisson's } \\
\text { ratio, } v\end{array}$ & 0.35 & 0.35 & 0.35 & 0.35 & 0.35 & 0.15 \\
\hline
\end{tabular}

${ }^{\mathrm{a}}$ Note: $\quad$ MC strength values were obtained from peak parameters from earlier direct shear testing on tunneling rock spoils, i.e. $c_{p}^{\prime}$ and $\phi_{p}^{\prime}$

${ }^{\mathrm{b}}$ Note: MC strength values for interface elements

${ }^{c}$ Note: Elastic stiffness of modeled concrete pipeline was artificially increased to isolate effects of pipe compression from interface shear stresses. 
Table 3. Material properties for finite element modeling of Drive B

\begin{tabular}{|c|c|c|c|c|c|c|}
\hline Material & $\begin{array}{c}\text { Firm silty } \\
\text { clay (SPT 6) }\end{array}$ & $\begin{array}{l}\text { Very stiff } \\
\text { silty clay } \\
\text { (SPT 18) }\end{array}$ & $\begin{array}{c}\text { Hard silty } \\
\text { clay (SPT 50) }\end{array}$ & Phyllite & $\begin{array}{l}\text { Rock-pipe } \\
\text { interface }\end{array}$ & Pipe \\
\hline $\begin{array}{l}\text { Elements } \\
\text { used }\end{array}$ & Soil & Soil & Soil & Soil & Interface & Plate \\
\hline $\begin{array}{l}\text { Material } \\
\text { model }\end{array}$ & $\mathrm{MC}$ & $\mathrm{MC}$ & $\mathrm{MC}$ & $\mathrm{MC}$ & $\mathrm{MC}$ & $\begin{array}{l}\text { Linear } \\
\text { elastic }\end{array}$ \\
\hline Depth (m) & 0 to 8.6 & 8.6 to 10.3 & 10.3 to 15 & 15 to 25 & - & - \\
\hline $\begin{array}{l}\text { Unit weight, } \gamma \\
\left(\mathrm{kN} / \mathrm{m}^{3}\right)\end{array}$ & 18 & 18 & 18 & 22 & - & 24 \\
\hline $\begin{array}{l}\text { Cohesion, } c^{\prime} \\
(\mathrm{kPa})\end{array}$ & 5 & 10 & 15 & $57.8^{\mathrm{a}}$ & 0 & - \\
\hline $\begin{array}{l}\text { Friction } \\
\text { angle, } \phi^{\prime}\left(^{\circ}\right)\end{array}$ & 28 & 28 & 30 & $44.3^{\mathrm{a}}$ & $4.57^{\mathrm{b}}$ & - \\
\hline $\begin{array}{l}\text { Elastic } \\
\text { modulus, } E \\
\left(\mathrm{kN} / \mathrm{m}^{2}\right)\end{array}$ & 13,200 & 19,800 & 55,000 & $7.1 \times 10^{6}$ & 1,000 & $27 \times 10^{9 c}$ \\
\hline $\begin{array}{l}\text { Poisson's } \\
\text { ratio, } v\end{array}$ & 0.35 & 0.35 & 0.35 & 0.35 & 0.35 & 0.15 \\
\hline
\end{tabular}

${ }^{\mathrm{a}}$ Note: $\quad \mathrm{MC}$ strength values were obtained from peak parameters from earlier direct shear testing on tunneling rock spoils, i.e. $c_{p}^{\prime}$ and $\phi_{p}^{\prime}$.

${ }^{\mathrm{b}}$ Note: MC strength values for interface elements

${ }^{c}$ Note: Elastic stiffness of modeled concrete pipeline was artificially increased to isolate effects of pipe compression from interface shear stresses. 
Table 4. Material properties for finite element modeling of Drive C

\begin{tabular}{|c|c|c|c|c|c|c|c|c|c|}
\hline Material & $\begin{array}{c}\text { Loose } \\
\text { sand } \\
\text { (SPT 8) }\end{array}$ & $\begin{array}{c}\text { Very } \\
\text { soft clay } \\
\text { (SPT 2) }\end{array}$ & $\begin{array}{c}\text { Loose } \\
\text { sand } \\
\text { (SPT 8) }\end{array}$ & $\begin{array}{c}\text { Dense } \\
\text { sand } \\
\text { (SPT 34) }\end{array}$ & $\begin{array}{l}\text { Medium } \\
\text { dense } \\
\text { sand } \\
\text { (SPT 19) }\end{array}$ & $\begin{array}{c}\text { Very } \\
\text { soft clay } \\
\text { (SPT 2) }\end{array}$ & Shale & $\begin{array}{l}\text { Rock- } \\
\text { pipe } \\
\text { interface }\end{array}$ & Pipe \\
\hline $\begin{array}{l}\text { Elements } \\
\text { used }\end{array}$ & Soil & Soil & Soil & Soil & Soil & Soil & Soil & Interface & Plate \\
\hline $\begin{array}{l}\text { Material } \\
\text { model }\end{array}$ & $\mathrm{MC}$ & $\mathrm{MC}$ & $\mathrm{MC}$ & $\mathrm{MC}$ & $\mathrm{MC}$ & $\mathrm{MC}$ & $\mathrm{MC}$ & $\mathrm{MC}$ & $\begin{array}{l}\text { Linear } \\
\text { elastic }\end{array}$ \\
\hline Depth (m) & 0 to 6.1 & $\begin{array}{c}6.1 \text { to } \\
10.5\end{array}$ & $\begin{array}{c}10.5 \text { to } \\
11.6\end{array}$ & $\begin{array}{c}11.6 \text { to } \\
13.5\end{array}$ & $\begin{array}{c}13.5 \text { to } \\
14.9\end{array}$ & $\begin{array}{c}13.5 \text { to } \\
19\end{array}$ & 19 to 30 & - & - \\
\hline $\begin{array}{l}\text { Unit } \\
\text { weight, } \gamma \\
\left(\mathrm{kN} / \mathrm{m}^{3}\right)\end{array}$ & 18 & 18 & 18 & 18 & 18 & 18 & 22 & - & 24 \\
\hline $\begin{array}{l}\text { Cohesion, } \\
c^{\prime}(\mathrm{kPa})\end{array}$ & 5 & 5 & 5 & 15 & 10 & 5 & $29.0^{\mathrm{a}}$ & 0 & - \\
\hline $\begin{array}{l}\text { Friction } \\
\text { angle, } \phi \text { ' } \\
\left(^{\circ}\right)\end{array}$ & 28 & 28 & 28 & 30 & 28 & 28 & $38.7^{\mathrm{a}}$ & $38.1^{\mathrm{b}}$ & - \\
\hline $\begin{array}{l}\text { Elastic } \\
\text { modulus, } \\
E^{\prime} \\
\left(\mathrm{kN} / \mathrm{m}^{2}\right)\end{array}$ & 13,910 & 2,200 & 13,910 & 59,130 & 33,040 & 2,200 & $7.1 \times 10^{6}$ & 1,000 & $27 \times 10^{9 c}$ \\
\hline $\begin{array}{l}\text { Poisson's } \\
\text { ratio, } v\end{array}$ & 0.35 & 0.35 & 0.35 & 0.35 & 0.35 & 0.35 & 0.35 & 0.35 & 0.15 \\
\hline
\end{tabular}

${ }^{\mathrm{a}}$ Note: $\mathrm{MC}$ strength values were obtained from peak parameters from earlier direct shear testing on tunneling rock spoils, i.e. $c_{p}^{\prime}$ and $\phi_{p}$.

${ }^{\mathrm{b}}$ Note: MC strength values for interface elements

${ }^{c}$ Note: Elastic stiffness of modeled concrete pipeline was artificially increased to isolate effects of pipe compression from interface shear stresses. 
Table 5. Analysis of finite element modeling results

\begin{tabular}{|c|c|c|c|}
\hline $\begin{array}{l}\text { Drive } \\
\text { Geology }\end{array}$ & $\begin{array}{c}\text { A } \\
\text { Sandstone }\end{array}$ & $\begin{array}{c}\text { B } \\
\text { Phyllite }\end{array}$ & $\begin{array}{c}\mathrm{C} \\
\text { Shale }\end{array}$ \\
\hline Prescribed displacement $(\mathrm{mm})$ & 100 & 100 & 100 \\
\hline Vertical stress acting on pipe crown, $\sigma_{E V}\left(\mathrm{kN} / \mathrm{m}^{2}\right)$ & $-20.8^{\mathrm{a}}$ & $-22.3^{\mathrm{a}}$ & 11.7 \\
\hline Arching ratio, AR (\%) & 6.2 & 5.3 & 8.6 \\
\hline Measured jacking forces, $J F_{\text {meas }}(\mathrm{kN} / \mathrm{m})$ & 14.4 & 4.8 & 81.1 \\
\hline Interface shear stress, $\tau_{1}\left(\mathrm{kN} / \mathrm{m}^{2}\right)$ & 44 & 14 & 133 \\
\hline $\begin{array}{l}\text { Jacking forces calculated from interface shear stresses, } J F_{\tau, \text { cal }} \\
(\mathrm{kN} / \mathrm{m})\end{array}$ & 12.4 & 4.2 & 63.8 \\
\hline Error, $\frac{J F_{\tau, c a l}-J F_{\text {meas }}}{J F_{\text {meas }}} \times 100(\%)$ & 12.4 & 13.8 & 21.4 \\
\hline Integration of $\tau_{1}$ along modeled pipeline $(\mathrm{kN})$ & 3953 & 1566 & 14875 \\
\hline Reaction force, $\Sigma F_{y}(\mathrm{kN})$ & 3727 & 1544 & 14630 \\
\hline Jacking forces calculated from reaction force, $J F_{F y, c a l}(\mathrm{kN} / \mathrm{m})$ & 11.6 & 4.1 & 62.7 \\
\hline Error, $\frac{J F_{F y, c a l}-J F_{\text {meas }}}{J F_{\text {meas }}} \times 100(\%)$ & 19.7 & 14.9 & 22.6 \\
\hline
\end{tabular}

${ }^{\mathrm{a}}$ Note: $\quad$ Negative value of $\sigma_{E V}$ was readjusted to zero. 